\title{
ALLELOPATHIC EFFECTS OF INVASIVE ALIEN SPECIES PARTHENIUM HYSTEROPHORUS L. ON SEED GERMINATION OF PADDY AND WHEAT
}

\author{
Binita Shrestha and Chandra Bahadur Thapa \\ Department of Botany, Prithvi Narayan Campus, Tribhuvan University, Pokhara Nepal \\ E-mail: binishrestha1995@gmail.com \\ cbthapadr@yahoo.com
}

\begin{abstract}
The invasive species are the major cause of crop loss, across the globe, mainly due to their allelopathic effects on the growth of crop plants. In this study, we explored the allelopathic effects of Parthenium hysterophorus on germination of two major cereal crops of Nepal, Rice (Oryza sativa) and Wheat (Triticum aestivum). The experiment was conducted at laboratory of Department of Botany, Prithivi Narayan Campus, Pokhara, Nepal during 2017. In laboratory, seeds of rice and wheat were treated with aqueous extracts of $P$. hysterophorus plant parts viz. root, stem, leaf, inflorescence and whole plant with concentration of 5, 10, 15 and 20\%. The experiment was laid out in a complete randomized design (CRD) in a factorial arrangement with three replicates of each test. The result suggests that the effect was more on wheat than on rice. The maximum inhibition in seed germination of rice was recorded by the inflorescence extract however, in wheat seed germination was inhibited by leaf extract. In both rice and wheat, roots were highly affected than shoots because root first encounters the toxic allelochemicals and absorbs it. The highest concentration $(20 \%)$ of leaf, inflorescence and whole plant extract was found to be most pernicious whereas root and stem were recorded to have little effects.
\end{abstract}

Key words : Alien species, allelopathy, invasive, germination.

\section{INTRODUCTION}

Invasive Alien Species (IAS) are introduced from foreign countries or the regions of the country either by intentionally or unintentionally due to human activity, that has encroached the native species as it has self- establishing capacity and has resulted in the clear changes in the native biodiversity (Masum et. al., 2013). IAS get successfully established in any ecosystem because of their special capacity like high growth rate, high reproductive potential, adaptive nature and allelopathy (Kholi and Rani, 1994). Among these, allelopathy plays a vital role to invade a new ecosystem (Callaway and
Aschehoug, 2000; Hierro and Callaway, 2003). Thus, allelopathy is the chemical effect of any plant or microorganism to the surrounding plant or microorganism species that is able to inhibit and stimulate their growth. Parthenium hysterophorous is one of the invasive alien species/weed that has a strong allelopathic effect on the other species. Now, this noxious weed is considered as the major threat to the native ecosystems.

Parthenium hysterophorous belongs to the plant family Asteraceae. It is an annual, erect and profusely branched herb. It is usually $50-150$ cm long, stem highly branched; leaf simple with 
profusely dissected leaflets; flower head occur on a corymb, phyllaries 10 in 2 series, ovate, dull white, $3-4 \mathrm{~mm}$ in diameter; disc floret; numerous, dull white; stamen-4, anther-exerted; ovary sterile; ray floret found just opposite to inner phyllaries only 5 ray florets per flower head, corolla obsolete, stamen-absent, stigmaparted, style short, ovary oval, dorsiventrally flattened. Fruit cypsela, each flower head bearing 5 cypselas, flat and triangular shape with thin, white, spoon shaped appendages (Maharjan, 2006). A mature plant can produce 15000-25000 seeds (Haseler, 1976: Joshi, 1991). Seeds can germinate immediately but if buried under soil, can remain viable even up to 4-6 years (Navie et al., 1998). Parthenium hysterophorus germinates during spring, produce flower and seeds throughout its life period and dies in winter (Adkins et al., 2014). This invasive plant can germinate, grow and flower at the varieties of climatic conditions, mostly favors warm climate. It can survive in a wide variety of soils like fertile (black, alkaline, cracking-clay soil), sandy loam, and clay loams (Adkins et al., 2014). Especially, the polluted area, pasture land, roadside and railways tracks, agricultural land nearby highways are suitable for the profuse growth of $P$. hysterophorous.

Parthenium hysterophorous is originated by the natural hybridization between $P$. confertum and P. bipinnatifidum (Nath 1998). It was supposed that the weed was native to Central America, the West Indies and South America (Picman and Picman, 1984) and later on has spread to many countries of Asia, Africa and Australia (Navie et al., 1996). It is an alien invasive weed species considered as the world's seventh most devastating and poisonous weed (Bezuneh, 2015). It is locally known as congress grass, carrot weed, bitter weeds, false ragweed, fever few, white top, in different parts of the world
(Bhowmik et al., 2007). Parthenium weed has now invaded more than 20 countries including 5 continents and many islands. South East Asia, the Pacific and Western Africa are likely to have the adverse effect of invasion by $\mathrm{P}$. hysterophorous

Parthenium hysterophorous is presumed to have entered Nepal with food grains, vehicles and imported goods from India because of the open boarder between India and Nepal. In Nepal, it is commonly called as Kanike ghash, Bethu ghans, padke phul (Tiwari et al. 2005). In Pokhara valley, it is also called as seto paati, as its leaves are similar to Artimisia (Tite pati) and this weed has white flowers. This insalubrious weed was first reported from Nepal by Hara et al., 1982 and the herbarium specimen was collected for the first time in 1967 by Malla from Trisuli (Tiwari et al., 2005). In the recent context of Nepal, this noxious weed has already encroached roadsides of most of the highways and pasture lands and are in the process. Similarly, in case of Pokhara Valley $P$. hysterophorous is seen usually in the dumping sides (Polluted area), on the roadways, play grounds (pasture land), etc., But it has not encroached the agricultural land yet which are far away from the roadways but the farm lands near transportation area are badly affected.

Rice (Oryza sativa) and Wheat (Triticum aestivum) are the two staple cereal crops grown in different parts of Nepal. The rapid spread of $P$. hysterophorous is likely to have an adverse effect on the growth of the major staple food crops, including rice and wheat. Thus, in this study, we aimed to investigate the allelopathic effects of $P$. hysterophorous on the germination and growth of two major cereal crops of Nepal.

\section{MATERIALS AND METHODS}

The experiment was conducted at the Botanical laboratory of Prithivi Narayan Campus, Pokhara. Mature (flowering) Parthenium hysterophorous 
were uprooted from five different areas of Pokhara valley; Chauthe, Chhorepatan, Hari Chowk, Malepatan and Sirjana Chowk. The collected plant samples were thoroughly washed with tap water to remove the soil and other particles. The plants were then separated into different parts like leaf, inflorescence, stem, root and whole plant and dried in an oven at about $70^{\circ} \mathrm{C}$. The different plant parts were packed properly in the air tight plastic bags for about five months. The seeds of Rice (local varietyGurdi) and Wheat (varieties WK 1204, Rampur composite) were also collected from different places of Pokhara. After five months, the cut small parts of the plant were grounded separately with pestle and mortar. Powdered and aqueous extracts were prepared by using the methods of Heisey (1990). Five, 10, 15 and 20 grams of each (leaf, inflorescence, root, stem and whole plant) plant part was weighted and $100 \mathrm{ml}$ distilled water was added. The solution was left for 24 hours for soaking at room temperature (21$25^{\circ} \mathrm{C}$ ). After 24 hours of soaking, it was filtered through muslin cloth followed by Whatman's no. 1 filter paper and hence extracts of 5, 10, 15 and $20 \%$ concentration solution were prepared. The seeds of Rice and Wheat were treated with $0.1 \%$ of Sodium hypochlorite for 2-3 minutes and then washed for several times with distill water for surface sterilization. Then, 10 seeds of rice and wheat were placed in a petridish (9 cm diameter) lined with Whatman's no. 1 filter papers and crop seeds were moistened by $10 \mathrm{ml}$ each of $5 \%, 10 \%, 15 \%$ and $20 \%$ aqueous extracts and distilled water (Control). The laboratory experiment comprised of 50 treatment of five different concentrations $(5 \%$, $10 \%, 15 \%$ and $20 \%$ along with distilled water that served as a control), for each of leaf, stem, root, inflorescence and whole plant with two crop seeds (Rice \& Wheat). The treatments were arranged in a complete randomized design (CRD) with 3 replications. All the replicates were kept on the bench of a laboratory with 12 hours supply of fluorescent light during the night. Seeds were considered to be germinated with the emergence of the radicle. Data on germinated seeds (in number) were collected from the next day of sowing to the seventh day. The average data obtained from the experiment in the laboratory was subjected to statistical analysis. Standard deviation was calculated using STDEV-statistical software (STDEV Version 7, 2008).

\section{RESULTS AND DISCUSSION}

\section{Effect of Parthenium hysterophorus extracts on seed germination of Rice}

Seed germination was observed to be affected by the treatment of extracts. The germination percentage declined with the increase in the concentration of different parts and whole plant of $P$. hysterophorus on rice. Inflorescence extract was more inhibitory as compared to the other parts. The percentage of inhibition by inflorescence extract as compared to control were $96.7 \pm 4.71,73.33 \pm 20.54,63.33 \pm 12.5$ and $60 \pm 8.2$ in $5 \%, 10 \%, 15 \%$ and $20 \%$ respectively. Also, the results showed that the different part of Parthenium differ in their allelopathic potential and found that crop species were also variously sensitive. However, at low concentration (5\%), all seeds were germinated in root, stem, leaf and whole plant extract except in inflorescence extract. Our current findings are consistent with the previous findings. Tedele (2002) found a low effect of inflorescence and leaf extract at the lowest $(1.0 \%)$ concentration on seed germination of teff. The root and stem extract of $P$. hysterophorus were recorded to have lower effect on rice seeding germination as compared to other extracts. Similarly, in the record of 
Tedele (2002), there was no adverse effect on teff seed germination with aqueous extracts from root and shoot of $P$. hysterophorus. As the concentration of extract increased, the rate if inhibition increased and 20\% concentration was found more severe than others whereas in root, stem, leaf and whole plant the pattern of inhibition was more or less similar but $20 \%$ extract concentration of whole plant was found to be more inhibitory than root, stem and leaf (Fig. 1)

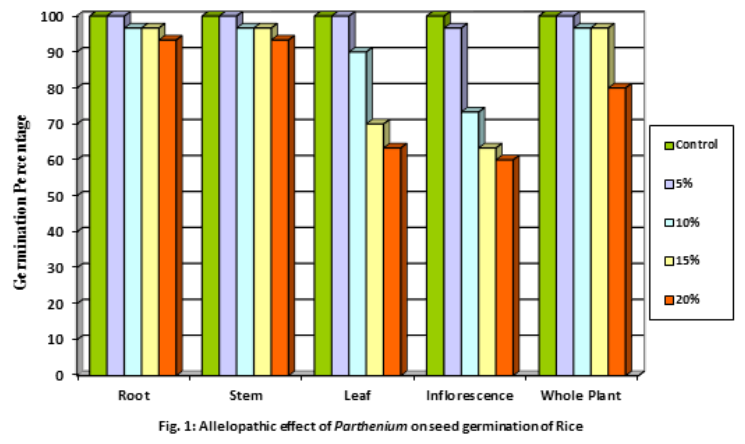

Effect of Parthenium hysterophorus extracts on seed germination of wheat

Allelopathy of P. hysterophorus showed intense suppression effects to wheat like in rice. In the highest concentration (20\%), of leaf extract was noted as the most harmful for wheat, as none of the seeds was germinated (Fig. 2); inhibition by leaf extract on wheat germination as compared to control were: $53.33 \pm 12.5,20 \pm 8.2,6.7 \pm 5$, zero (0) in $5,10,15$, and $20 \%$ respectively. Then the whole plant, inflorescence, stem and root were observed to be notorious to wheat respectively. Even in lower concentration 5\%, seed germination was highly affected. While in case of rice, lower concentration hadn't such pronounced effect, this might be due to different allelopathy potential on different species. Species-species variation in reaction to aqueous extract of $P$. hysterophorus was reported in previous studies (Srivastava et al., 1985;
Mersie and Singh, 1987; Kohli et al., 1996 and Kidanie, 2011). As the concentration increases, the rate of germination declines (Fig. 2).

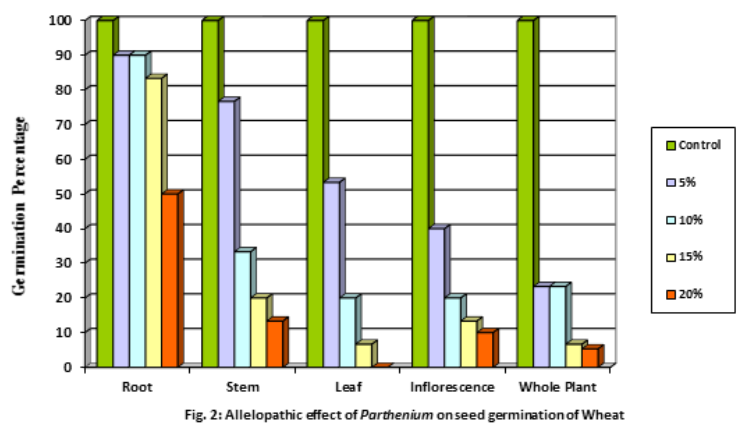

\section{CONCLUSIONS}

We found that the extract of $P$. hysterophorus has a significant adverse effect on the germination of two major staple crops of Nepal. Considering its high rate of invasion across the agricultural lands in Nepal and its inhibitory effect on the growth of Rice and Wheat, its eradication should be taken into a high priority. If this invasive herb is not controlled properly, it would cause a devasting threat to the Nepalese staple crops, leading to an adverse effect on our food security.

\section{ACKNOWLEDGMENTS}

We are thankful to the Department of Botany, Prithvi Narayan Campus, for providing laboratory facilities. We highly acknowledge the contribution of an anonymous reviewer to improve the standard of this manuscript.

\section{REFERENCES}

Adkins S.W, S Sangita., S Asad., B.B. Shrestha (2014). The Biology and Management of Parthenium weed Now Affecting the Native and Agro-Ecosystems of Nepal. Proc. of the International Conference on Invasive Alien Species Management, 23-29

Bhowmik P.C. and J.D. Doll (2007). Allelopathic effect of annual weed residues on growth and its potential management. Ecoprint 
14:1-17

Bezuneh T.T. (2015). Phytochemical and Antimicrobial Activity of Parthenium hysterophorous L.: A Review. Science Journal of Analytical Chemistry, 3(3):3038. doi;10.11648/j.sjac.20150303.11

Callaway R.M. and E.T. Aschehoug (2000). Invasive plants versus their new and old neighbours: a mechanism for exotic invasion. Science, 290: 521-523

Haseler, W. H. (1976). Parthenium hysterophorous L. in Australia. Pest Articles \& News Summaries (PANS). 22: 515-517

Heisey R.M. (1990). Allelopathic and herbicidal effects of extracts from tree of heaven Ailenthus alfissima. American J. Bot. 77: 662-670

Hierro J.L. and R.M. Callaway (2003). Allelopathy and exotic plant invasion. Plant and Soil 256: 29-39

Joshi, S., (1991). Interference effect of Cassia uniflora Mill. On Parthenium hysterophorous L. Plant and Soil. 132: 215223

Kidanie A.B. (2011). Allelopathic effects of Parthenium hyterophorus L. on Germination, Seedling Growth and Biomass production of Chickpea and Sesame; M.Sc Thesis, Haramaya University

Kohli R.K., D. Rani, H.P. Singh and S. Kumar (1996). Response of crop seeds towards the leafleachates of Parthenium hysterophorous L. Indian Jouranl of Weed Science, 28: 104106

Maharjan, S. (2006). Phenology, leaf attributes and allelopathic potential of Parthenium hysterophorous L., a highly allergic invasive weed in Kathmandu valley, M.Sc. Thesis, Central Department of Botany, Tribhuwan University.
Masum S.M., H. Mirza and M.H. Ali (2013). Threats of Parthenium hysterophorous on agroecosystems and its management: a review. International Journal of Agriculture and crop sciences, 6(11), 684-697.

Mersie, W. and M. Singh (1987). Allelopathic effect of Parthenium (Parthenium hysterophorus L.,) extract and residue on some agronomic crops and weeds. Journal of Chemical Ecology, 13: 1739-1747

Nath, R. (1988). Parthenium hysterophorous L.-A Review. Agricultural Review 9(4): 171-179

Picman J. and A.K. Picman (1984). Autotoxicity in Parthenium hysterophorous and its possible role in the control of germination. Biological Systematics and Ecology, 12:287-92

Srivastava, J.N., J.P. Shukla and R.C. Srivastava (1985). Effect of Parthenium hysterophorus L., extract on the seed germination and seedling growth of barley, pea, and wheat. Acta Bot Indica, 13: 194-197

Tedele(2002).Allelopathic effects of Parthenium hysterophorous on seed germination and seedling growth of Eragrostis tef. Journal of Agronomy and Crop Science, 188: 306-310

Tiwari S., B. Adhikari, M. Siwakoti, and K Subedi (2005). An Inventory and Assessment of Invasive Alien Plant Species of Nepal. IUCN- The World Conservation Union, Nepal.

\footnotetext{
Received 18 Feb 2018, Revised accepted 13 July 2018
} 